\title{
Contribuições de Paulo Freire frente o cotidiano midiático discente
}

\author{
Claudia de Jesus Tietsche Reis \\ Orcid: https://orcid.org/0000-0002-2057-5560 \\ Maria Antonia Ramos de Azevedo ${ }^{2}$ \\ Orcid: https://orcid.org/0000-0002-6215-2902
}

\section{Resumo}

Este artigo apresenta resultados de uma pesquisa realizada numa escola freiriana diante do cotidiano midiático discente e seus desafios educacionais. A partir de uma abordagem qualitativa analisou-se o projeto político pedagógico de uma escola freiriana e foram utilizadas entrevistas semiestruturadas com a equipe gestora e três professoras do ensino fundamental. Utilizou-se para análise dos dados coletados o método paradigma indiciário proposto por Carlo Ginzburg (1989). Concluiu-se que os princípios pedagógicos freirianos contribuem para incentivar a autonomia dos professores e considerar o contexto social como base formativa para a construção do indivíduo. Ao promover a interdisciplinaridade dos conteúdos praticados em forma de projetos que se modificam ano a ano, possibilita-se estar atento aos interesses dos alunos. Freire (2014a), ao propor que o sujeito deva reconhecer sua inconclusão em permanente movimento na história, viabiliza a abertura ao mundo e aos outros em uma relação dialógica constante.

Palavras-chave: Freire. Cotidiano Discente. Autonomia Docente.

\begin{abstract}
This article presents the results of a research carried out in Paulo Freire's school in the face of the student's daily media and its educational challenges. From a qualitative approach, the political pedagogical project of a Freire's school was analyzed and semi-structured interviewees were used with the management team and three elementary school teachers. For the analysis of the collected data, the method of the indicative paradigm proposed by Carlo Ginzburg (1989) was used. It was concluded that Freire's pedagogical principles contribute to encourage the autonomy of teachers and consider the social context as a formative basis for the construction of the individual. By promoting the interdisciplinarity of the contents practiced in the form of projects that change from year to year, it is possible to be attentive to the students' interests. Freire (2014a), by proposing that the subject should recognize his inconclusion in permanent movement in history, enables the opening to the world and to others in a constant dialogical relationship.
\end{abstract}

Keywords: Freire. Everyday Student. Teaching Autonomy.

\footnotetext{
${ }^{1}$ Doutoranda em Educação, UFSC - Florianópolis. E-mail: claudia.tietsche@gmail.com.

${ }^{2}$ Doutora em Educação, UNESP - Rio Claro. E-mail: maria.antonia@unesp.com.
} 


\section{Introdução}

O contexto educacional no século XXI ultrapassa a era informacional e alcança uma sociedade de aprendizagem e conhecimento contínuos, que nos exige conviver com novas formas de comunicação, como a leitura de textos audiovisuais e hipertextos, tornando o acesso a elas, através de uma participação crítica e criativa, um direito cidadão fundamental (MARTÍN-BARBERO, 2014). O cotidiano discente imerso nas mídias interativas solicita à escola possibilidades de socialização e compartilhamentos que dialoguem com sua realidade comunicacional (SIBILIA, 2012).

Nesta pesquisa, buscamos referências que pudessem auxiliar a prática docente diante deste novo contexto discente e esta investigação apontou para os princípios pedagógicos de Paulo Freire, uma vez que este defende que "ensinar exige respeito à autonomia do ser educando, como um imperativo ético e não um favor que podemos ou não conceder uns aos outros" (FREIRE, 2014a, p. 58). Neles exploramos pistas de convergência entre a atual necessidade dos alunos e a prática docente.

A cognição humana apresenta novas maneiras de processar a cultura, novos hábitos mentais, a partir da "ecologia midiática hipermóvel" (SANTAELLA, 2013), as novas tecnologias apresentam novos espaços de conhecimento e também de reconstrução de conhecimentos. Ao observarmos o comportamento dos alunos, há uma indicação clara de que "o espaço da aprendizagem é aqui, em qualquer lugar; o tempo de aprender é hoje e sempre" (GADOTTI, 2011, p. 24). Os alunos necessitam se sentir sujeitos ativos da aprendizagem, fazendo do professor um aprendiz permanente, um construtor de sentidos.

Uma docência que prime pela qualidade formativa não pode limitar o professor a distribuir tarefas, cumprir conteúdos curriculares e estar desprovida de significância e sentido diante da realidade dos discentes e o contexto midiático que cerca a vida das pessoas. Frente a isso, cabe ao professor, na sua prática docente, ressignificar os seus saberes compreendendo o valor da escuta atenta aos discentes; refletir de forma permanente sobre seu trabalho; entender que sua ação está fortemente vinculada ao discente e, consequentemente, ao seu contexto sóciohistórico, cultural e midiático; papel fundante para a construção da cidadania de todos os envolvidos.

Assim; os princípios pedagógicos freirianos contribuem para a busca da autonomia dos professores ao considerarem o contexto social como base formativa para a construção do indivíduo. Ao promover a interdisciplinaridade dos conteúdos praticados em forma de projetos que se modificam ano a ano, possibilita-se estar atento aos interesses dos alunos em sua realidade.

\section{Metodologia}

Como caminho metodológico optamos por uma abordagem qualitativa para o desenvolvimento de um trabalho de campo com coleta de dados por meio de análise documental e entrevistas semiestruturadas (LÜDKE; ANDRÉ, 2011) em uma escola freiriana do interior paulista.

Para a análise documental o foco foi o Projeto Político Pedagógico (PPP) da instituição, sendo analisada a estrutura do documento, e os itens que o compunham, investigando assim, tanto a forma como o conteúdo da proposta formativa ali contida. As duas categorias de análises do documento voltaram-se para o detalhamento dos itens e/ou a falta deles; e o destrinchar da teoria pedagógica que sustentava tal proposta.

$\mathrm{Na}$ pesquisa de campo, foram entrevistados um representante da equipe gestora e três professoras do ensino fundamental, por meio de um roteiro semiestruturado cujo foco estava 
voltado a trazer detalhamentos da prática pedagógica vinculados ao PPP; e às reflexões acerca dos processos de ensino e aprendizagem mediante o cotidiano midiático discente.

Para o processo de discussão de pistas, sinais ou indícios reveladores de fenômenos da realidade, escolhemos os paradigmas indiciários de Ginzburg (1989) como forma de percepção dos gestos, expressões, entonações, sinais não verbais, hesitações, alterações de ritmo, enfim, toda uma comunicação não verbal cuja captação é muito importante para a compreensão e a validação do que foi efetivamente dito (LÜDKE; ANDRÉ, 2011). Por conseguinte, a análise dos dados teve como respaldo os princípios da pedagogia de Paulo Freire balizadas pelo conceito de linguagem, contextualização, problematização, saberes da prática pedagógica e a interrelação Homem-Mundo-Sociedade e Conhecimento.

\section{Resultados e Discussão}

A primeira pessoa entrevistada como representante da equipe gestora foi a coordenadora pedagógica, professora fundadora da instituição e aluna de Paulo Freire em uma das disciplinas de seu mestrado em educação pela Pontifícia Universidade Católica de São Paulo (PUCSP). Através dessa entrevista semiestruturada e da análise documental do PPP foi possível caracterizarmos o contexto educacional desta escola freireana.

A escola foi fundada em 1993 por iniciativa de um grupo de pais que desejava uma educação em perspectiva freireana para seus filhos. O nome da escola foi autorizado por seu patrono, Paulo Freire, que em visita realizada em 1995 disse: "Cheguei. Vi. Perguntei. Espantei-me. Gostei. Voltarei”. Infelizmente Paulo Freire não voltou, já que faleceu dois anos depois.

A escola é uma cooperativa, ou seja, é uma entidade composta por pessoas físicas ou jurídicas, com determinada finalidade comum. Todos os integrantes de uma cooperativa são sócios e todos têm o mesmo poder de voto. A cooperativa tem regramento jurídico próprio, com diversos benefícios legais. Além disso, cada um dos associados pode ter o direito na tomada de decisões da referida sociedade, de acordo com os termos de sua constituição. O principal documento que rege uma cooperativa é seu Estatuto Social, o qual deve ser registrado junto aos órgãos governamentais competentes.

Conforme previsto no Estatuto, a cooperativa desta escola freireana tem vários objetivos, sendo o principal a prestação de serviços na área educacional e do ensino de caráter comum ou especial aos seus cooperados, cônjuges, filhos e dependentes, ou ainda, a pessoa de sua indicação. A cooperativa é administrada através do Conselho de Administração, do Conselho Pedagógico e do Conselho Fiscal. O Conselho de Administração é composto por cinco pessoas, o Diretor Presidente, o Diretor Secretário, o Diretor Financeiro e de Patrimônio e dois suplentes. Seu mandato é de três anos. Suas principais funções são planejar e acompanhar o funcionamento da cooperativa quanto ao regulamento interno, ao Plano Diretor de Educação, aos recursos financeiros, às contratações, aos cooperados, à assembleia geral. O Conselho Pedagógico é o órgão responsável pela definição da política educacional a ser aplicada pela cooperativa. É composto pelo Diretor Presidente, Diretores da Escola, Coordenadores Pedagógicos, professores e pais. E o Conselho Fiscal é o órgão que fiscaliza a administração da cooperativa. É composto por três membros, com mandato de um ano, sendo composto pelo presidente, secretário e um suplente. O Estatuto tenta estabelecer um diálogo horizontal entre seus membros:

Ao fundar-se no amor, na humildade, na fé nos homens, o diálogo se faz uma relação horizontal, em que confiança de um polo no outro é consequência óbvia. Seria uma contradição se, amoroso, humilde e cheio de fé, o diálogo não provocasse este clima de confiança entre seus sujeitos (FREIRE, 2014b, p. 113). 
No ano da coleta de dados em 2013, a escola possuía cerca de duzentos e trinta alunos; em média, vinte alunos por sala, distribuídos na educação infantil, ensino fundamental e médio. A escola oferece educação integral para os alunos da educação infantil e ensino fundamental I, do $1^{\circ}$ ao $5^{\circ}$ ano, com a proposta de oferecer vivências em que estão presentes a arte, o corpo e o desejo de conhecer.

Segundo a equipe gestora, sua proposta pedagógica desperta nos alunos a curiosidade, o espírito investigador, a criatividade e a análise crítica. É caracterizada por um processo amplo de formação humana, em que se trabalha com projetos que consideram os interesses dos alunos, assim como o diálogo com seu saber prévio, na construção de novos conhecimentos que façam sentido para cada um, possibilitando o conhecer com liberdade e autonomia.

A coordenadora pedagógica fez questão de destacar que o principal diferencial da escola é a disciplina de filosofia, que inicia desde o primeiro ano e vai até o $3^{\circ}$ ano do ensino médio; portanto, do fundamental I e II até o médio. Por ser uma escola freireana existe uma preocupação com a filosofia e os conceitos de Paulo Freire, como: criticidade, autonomia, respeito, aprendizagem, o ritmo e o desenvolvimento do aluno.

O processo de alfabetização contextualizado está presente no discurso da equipe gestora, assim como a preocupação com a criatividade dos alunos, a partir do despertar de sua curiosidade. Não existe um método, uma apostila, uma cartilha; mas um compromisso com a prática pedagógica relevante à realidade de seus alunos. Segundo a coordenadora pedagógica o foco principal é na participação dos alunos durante todo o período no ambiente escolar. Inclusive a escola disponibiliza rede local sem fio gratuitamente para que os alunos utilizem nos intervalos ou sobre orientação dos professores. A equipe acredita ser uma oportunidade de trabalhar a autonomia, a liberdade, o respeito ao professor e colega; além de demonstrar confiança em seus professores que têm a liberdade de trabalhar em concordância com o que acham importante naquela idade, série e conteúdo.

Como manifestação presente à experiência vital, a curiosidade humana vem sendo histórica e socialmente construída e reconstruída. Precisamente porque a promoção da ingenuidade para a criticidade não se dá automaticamente, uma das tarefas precípuas da prática educativo-progressista é exatamente o desenvolvimento da curiosidade crítica, insatisfeita, indócil. Curiosidade com que podemos nos defender de "irracionalismos" decorrentes $d o$ ou produzidos por certo excesso de "racionalidade" de nosso tempo altamente tecnologizado. E não vai nesta consideração nenhuma arrancada falsamente humanista de negação da tecnologia e da ciência. Pelo contrário, é consideração de quem, de um lado, não diviniza a tecnologia, mas, de outro, não a diaboliza. De quem a olha ou mesmo a espreita de forma criticamente curiosa (FREIRE, 2014a, p.33-34).

Os professores se reúnem formalmente uma vez por semana, todas às quartas-feiras, e nesses encontros discutem temas diversos, inclusive sobre as mídias. Por exemplo, como conduzir uma pesquisa utilizando a internet como ferramenta. Os professores indicam como pesquisar, alertam sobre determinados sites. Existe essa conversa entre os professores sobre a qualidade dos sites, para desmistificar que nem tudo que está na internet é verdadeiro. A equipe gestora defende que utilizar as mídias com naturalidade é uma maneira de chegar mais perto dos alunos, de se comunicar com eles.

Além da equipe gestora, foram entrevistadas três professoras do $1^{\circ}, 5^{\circ}$ e $9^{\circ}$ ano do ensino fundamental, para abranger o início, o meio e o fim do $1^{\circ}$ grau. $\mathrm{O} 1^{\circ}$ ano escolar representa a transição da educação infantil para o ciclo I do ensino fundamental; o $5^{\circ}$ ano escolar retrata a transição entre o ciclo I e o ciclo II do ensino fundamental; e o $9^{\circ}$ ano simboliza a transição do ensino fundamental para o ensino médio. A partir dos dados coletados nas entrevistas, no PPP 
e na revisão bibliográfica do processo de desenvolvimento da pesquisa, emergiram-se três dimensões de análise.

Mediante as categorias de análises pontuadas tanto na análise dos PPP quanto das entrevistas semiestruturadas realizadas foi possível que fossem emergindo delas algumas dimensões. A primeira dimensão é a da prática descrita pelas professoras entrevistadas e apresentada pelo PPP - aspecto material da linguagem; a segunda dimensão é do cotidiano midiático discente - aspecto institucional da historicidade; e a terceira e última dimensão traz contribuições dos princípios pedagógicos de Paulo Freire - aspecto epistêmico da ideologia.

A ideologia é entendida como o posicionamento do sujeito quando se filia a um discurso, sendo o processo de constituição do imaginário que está no inconsciente, ou seja, o sistema de ideias que constitui a representação; a história representa o contexto sócio-histórico e a linguagem é a materialidade do texto gerando "pistas" do sentido que o sujeito pretende dar (CAREGNATO; MUTTI 2006, p. 680).

Para a análise dos dados valorizamos os sentimentos que emergiram da fala dos participantes, suas vivências durante o processo de construção de suas respectivas biografias, a subjetividade do grupo e a valorização dos saberes da experiência que por meio da reflexão diária do ato pedagógico acabam por agregar conhecimentos que auxiliam a qualificação da docência num constante espiral de aprendizagens vindo, assim, ao encontro de outro princípio freiriano fundamental: a reflexão sistemática de cada ato pedagógico vivido.

\section{Prática descrita pelas professoras entrevistadas e apresentada pelo PPP - aspecto material da LINGUAGEM}

O impulso à pergunta caracteriza sua boniteza, adjetivo muito utilizado por Paulo Freire ao falar de educação. Por ser passível a mudanças e flexível a evoluções, nossa curiosidade foi saber como a prática pedagógica freiriana pode promover a autonomia diante da influência das mídias no contexto dos alunos. Freire (2014b) afirma que a curiosidade como inquietação indagadora, como inclinação ao desvelamento de algo, como pergunta verbalizada ou não, como procura de esclarecimento, como sinal de atenção que sugere alerta, faz parte integrante do fenômeno vital.

Na história de fundação da escola pesquisada constatou-se uma construção coletiva por iniciativa de um grupo de pais que desejava uma educação diferenciada para seus filhos. A escola se constituiu repleta de significâncias para aquele grupo que optou por uma ideologia humanista, uma releitura contextualizada dialógica dos princípios pedagógicos de Paulo Freire.

Em sua formação discursiva, o PPP apresentado reflete o interesse daquele grupo por determinada ideologia, e se concretiza a partir da linguagem interpretativa influenciada pelo seu contexto, como: localidade, condições econômicas, interesses políticos, relações sociais, crenças e opiniões. Orlandi (2009, p.43) afirma que "a formação discursiva se define como aquilo que numa formação ideológica dada - ou seja, a partir de uma posição dada em uma conjuntura sócio-histórica dada - determina o que pode e deve ser dito".

Um dado interessante e comum nas respostas das professoras foi o entusiasmo e a esperança no processo educacional. Em seus discursos com palavras distintas, expressaram claramente que perseverar na educação é uma escolha prazerosa. Balizaram suas permanências em expressões que revelaram seus interesses pessoais. Por exemplo a professora do $9^{\circ}$ ano, que ao ser perguntada sobre o que significava ser professora, afirmou que era seu alimento para a vida.

É digna de nota a capacidade que tem a experiência pedagógica para despertar, estimular e desenvolver em nós o gosto de querer bem e o gosto da alegria, 
sem a qual a prática educativa perde o sentido. É esta forma misteriosa, às vezes chamada vocação, que explica a quase devoção com que a grande maioria do magistério nele permanece, apesar da imoralidade dos salários (FREIRE 2014a, p. 139).

Quando questionada sobre as atividades que desenvolve, a professora do $5^{\circ}$ ano respondeu de forma coletiva, afirmando que a escola trabalhava com projetos, em que todas as disciplinas interagiam sobre o mesmo tema. Interagir, integrar, relacionar, conviver, dialogar são verbos que substanciados ou adjetivados, estão presentes na proposta pedagógica e realçam a conversa presente entre teoria e prática. $\mathrm{O}$ projeto político pedagógico da escola freiriana afirma:

Trabalhamos com projetos que consideram os interesses dos alunos, assim como o diálogo com seu saber prévio, na construção de novos conhecimentos que façam sentido para cada um, possibilitando o conhecer com liberdade e autonomia. O trabalho por projetos tem como perspectiva curricular o estabelecimento das relações existentes entre as diferentes áreas de conhecimento, permitindo ao aluno a compreensão de que as disciplinas escolares não são categorias distintas no mundo e nas muitas possibilidades de compreendê-lo (PPP da escola freiriana pesquisada vigente em 2014).

Respeito e responsabilidade com o próximo permeiam o discurso das professoras entrevistadas e refletem o que encontramos na pesquisa bibliográfica que baliza a prática pedagógica de Paulo Freire. Mais um exemplo foi a fala da professora do $1^{\mathrm{o}}$ ano:

Apesar de sermos uma escola particular é uma cooperativa. Nós falamos muito do cooperativismo, para eles cooperarem com a limpeza e a organização da escola; porque a escola também é deles. Além disso, a autonomia, a criticidade, a liberdade e o respeito ao próximo são evidenciados.

Segundo Freire (2014b) a ética do ser humano é presente a partir do momento que tomamos consciência do nosso inacabamento e assim podemos respeitar a autonomia e a dignidade de cada um. A interpretação do discurso é o vestígio do possível. É o lugar próprio da ideologia e é materializada pela história. Ela sempre se dá de algum lugar da história e da sociedade. A interpretação é assumida, como um gesto simbólico que dá sentido fazendo a significação. Sempre existirá uma interpretação para dar visibilidade ao sentido que o sujeito pretendeu transmitir no seu discurso.

Nessa direção, os conteúdos da proposta pedagógica da escola trazem a dimensão do valor da construção coletiva de ações pedagógicas tanto no âmbito da organização do trabalho pedagógico dos professores como, também, como ação coletivizada que deva ser exercida dentro dos processos de ensino e aprendizagem dos professores junto aos alunos, como propostas humanísticas buscam alcançar. Isso aponta o princípio que norteia essa escola que é a grande alavanca da ação educativa: o homem valorizado na sua integralidade, na sua totalidade e na sua individualidade.

\section{Cotidiano midiático discente - aspecto institucional da HISTORICIDADE}

Depois de passar pelo aspecto material da linguagem dessa escola, que se mostra pelo discurso de seus professores e conteúdo de sua proposta pedagógica, o aspecto institucional da sociedade, revela-se em sua historicidade.

Já se disse que, num certo sentido, a História é sempre a história atual, isto é, a organização do passado tal como o vemos com os olhos do presente. Assim, 
corremos todos um inevitável risco sempre que tentamos relatar fatos ou ideias, ou entender as marcas deixadas pelo homem ao longo do tempo - o risco de fazer do passado apenas um espelho do nosso tempo. Que história então, é possível narrar? Uma história que, mesmo reconhecendo a distância que nos separa do passado, dele restitua aquilo que ainda apresenta significados vivos para nós. Nesse sentido, é a evolução da cultura que permite, em maior escala, um diálogo proveitoso entre a tradição de ontem e as inquietações de hoje (VALVERDE, 1987, p. 1).

Os avanços tecnológicos permitiram e permitem que a roda continue a virar, que o homem possa voar e mergulhar intrigado e inspirado pela observação da natureza, que a história possa ser contada e recontada; enfim, que a evolução perpetue. Nosso objetivo é, com criticidade, reconhecer a historicidade das mídias na sociedade, principalmente, sua utilização pelas crianças e jovens, entre seis e quinze anos, idade escolar do ensino fundamental.

Ao garimpar na literatura, conteúdos que expressassem a utilização dos meios eletrônicos pelas crianças e jovens, para compreender sua influência no comportamento, encontramos uma enciclopédia intitulada $O$ mundo da criança, orientação para o desenvolvimento da criança publicada em 1949. No volume 13, o capítulo A Criança e o Rádio já traz uma preocupação com este novo meio eletrônico de comunicação:

Felizes decerto são os que vivem nesta época; não obstante, as pessoas ainda precisam aprender como fazer melhor uso deste novo meio de comunicação. Devem aprender como solucionar os problemas que apresenta, e antes fazer dele um servo do que permitir que seja um senhor. Este é um apelo especial para os pais cuja tarefa é guiar o uso que seu filho faz do rádio (DUVAL, 1949, p. 228-229).

Mais de setenta anos atrás, quando se iniciava a inserção das mídias como meios de comunicação, a preocupação persevera e a pergunta persiste: Somos servos ou senhores destes meios? Ainda no mesmo capítulo citado, aborda-se uma reflexão sobre o rádio versus brincadeiras ao ar livre:

Primeiramente, os pais devem considerar qual o valor da brincadeira ao ar livre. As crianças que estão em crescimento necessitam de sol e ar fresco. Há muitas tardes, entretanto, em que não há sol quente e em que o ar puro está contaminado de fumaça e fuligem. Brincadeiras ao ar livre em tais dias são de valor duvidoso quanto ao ar puro e sol radiante. As crianças precisam de atividades de todo o seu corpo e brincadeiras ativas. Este tipo robusto de brincadeira requer espaço para correr e pular. Depois de um dia passado na carteira do colégio, a maioria das crianças deve ter um período ativo de brincadeira fora de casa. A amplitude deste período depende da criança, individualmente, e do tipo de programa do colégio, que também faz diferença. Há alguns colégios que oferecem uma sadia variedade de brincadeiras ativas e sossegadas durante o dia letivo, de forma que a criança não precisa de tanta atividade integral logo que o colégio a dispensa (DUVAL, 1949, p. 234-235).

Consideramos de suma relevância este trecho, porque indica uma realidade inversa a nossa. Enquanto na década de cinquenta, a promoção de movimento e brincadeiras ao ar livre era dada fora da escola; hoje, com a utilização da televisão, do videogame, do computador/internet, ou dos celulares que contêm todos os exemplos anteriores, as crianças e jovens precisam se movimentar, vivenciar os conteúdos com toda a sua corporeidade dentro das escolas. A necessidade de expansão inverteu de lugar, e as escolas que possibilitam o 
contato, o movimento e a expressão dos e entre os alunos são essenciais no desenvolvimento deles.

Reconhecer e compreender o contexto dos alunos direcionam práticas pedagógicas, que possam harmonizar a realidade com as vivências conduzidas na escola. Para Melo e Tosta (2008) a escola desempenha, no decorrer da História e sendo fruto desta, três papeis distintos: redentora da sociedade, lugar onde as crianças aprenderiam o sentido da coletividade; reprodutora das desigualdades sociais, ao inculcar valores e criar hábitos; e transformadora da sociedade, um mecanismo social capaz de promover mudança.

\begin{abstract}
Exemplo disso são os professores que, no lugar de adotarem uma postura de simples negação da mídia ou de crítica ingênua (aquela que atribui aos meios de comunicação todas as mazelas da sociedade e toma a mídia como um "demônio"), procuram estudar o fenômeno midiático e integram em seu currículo, formal ou informalmente, o debate que está posto. Seja porque os alunos estão expostos à mídia permanentemente e trazem marcas de sua influência no cotidiano escolar, seja porque o professor, não desconhecendo essa realidade, incorpora em sua prática docente o que a mídia oferece como conteúdo a ser discutido em sala. Assim, ele deve exercer seu papel de mediador na elaboração crítica e criativa de critérios de leitura das formas simbólicas ofertadas pelos meios de comunicação e tecnologias digitais (MELO; TOSTA 2008, p. 24).
\end{abstract}

Se as mídias de comunicação são os aparatos de mediação social da atualidade, o professor desde sua formação inicial e continuada, deve se preparar para desenvolver com seus alunos processos de mediação, reconhecendo e compreendendo esses meios. Utilizá-los ou não em suas práticas é uma escolha que dependerá das realidades individuais das escolas, encabeçadas pela prática dialógica de seus professores.

Freire não publicou apontamentos específicos sobre mídias e educação, mas direcionamentos que possibilitam interpretações diversas. Em seu livro Pedagogia da Autonomia, Freire (2014a) chama o nosso tempo de altamente tecnologizado e aponta a responsabilidade dos educadores em desenvolver curiosidade crítica, insatisfeita e indócil em seus alunos como antídoto contra a alienação irracional. As professoras da escola freireana verbalizaram diretamente suas relações práticas com os alunos diante dessa temática. $\mathrm{E}$ convergiram ao afirmarem que a promoção da vivência social é um objetivo da escola, independente do uso ou não das mídias, que, se necessário, poderão ser utilizadas com naturalidade em um processo dialógico docente-discente. A base formativa se enraíza no contexto de todo o entorno.

\title{
Contribuições dos princípios pedagógicos de Paulo Freire - aspecto epistêmico de sua IDEOLOGIA
}

Com os aspectos material e institucional identificados, falta reconhecer o aspecto epistêmico, o qual se relaciona com a ideologia desta pedagogia, as projeções de sentido realizadas pelos sujeitos quanto à influência do cotidiano midiático discente.

Freire faz referência à ideologia, caracterizando sua incompletude e seu bálsamo de significâncias interpretativas e não palpáveis, como a complexidade que abarca um ser humano; portanto, pertinentes para a autonomia que possibilita a liberdade.

O poder da ideologia me faz pensar nessas manhãs orvalhadas de nevoeiro em que mal vemos o perfil dos ciprestes como sombras que parecem muito mais manchas das sombras mesmas. Sabemos que há algo metido na penumbra mas não o divisamos bem. A própria "miopia" que nos acomete dificulta a 
percepção mais clara, mais nítida da sombra. Mais séria ainda é a responsabilidade que temos de docilmente aceitar que o que vemos e ouvimos é o que na verdade é, e não a verdade distorcida. A capacidade de penumbrar a realidade, de nos "miopizar", de nos ensurdecer que tem a ideologia nos faz, por exemplo, a muitos de nós, aceitar docilmente o discurso cinicamente fatalista neoliberal que proclama ser o desemprego no mundo uma desgraça do fim do século. Ou que os sonhos morreram e que o válido hoje é o "pragmatismo" pedagógico, é o trino técnico-científico do educando e não sua formação de que já se fala. Formação que, incluindo a preparação técnicocientífica, vai mais além dela (FREIRE, 2014a, p. 123).

Em sua concepção de ideologia, o autor vê com restrição seu conceito. Critica a ideologia cega, assim como alerta para a individualidade interpretativa que a cerca. Apresenta pistas que não a nega, mas que a passividade não pode ser sua parceira, e sim, um pensar ativo sobre ela, pautado pelo respeito às diferenças.

Para me resguardar das artimanhas da ideologia, não posso nem devo me fechar aos outros, nem tampouco me enclausurar no ciclo da minha verdade. Pelo contrário, o melhor caminho para guardar viva e desperta a minha capacidade de pensar certo, de ver com acuidade, de ouvir com respeito, por isso de forma exigente, é me deixar exposto às diferenças, é recusar posições dogmáticas, em que me admita como proprietário da verdade (FREIRE, 2014a, p. 131).

Ao pedirmos que as professoras apontassem as influências das mídias no cotidiano dos alunos do ensino fundamental e quanto essa influência interfere no seu papel como professor, as respostas evidenciaram naturalidade ao tratar do tema, reconhecendo a influência dos novos meios de comunicação; porém, incorporando o assunto em conversas ou debates durante suas práticas.

Na sala de aula eu não utilizo nada de meios eletrônicos. No máximo para mostrar uma música ou um vídeo através do notebook. O que eu percebo é que as crianças estão mais nesse mundo virtual. Em uma roda de conversa sobre o final de semana, eles falam que brincaram com o tablete, jogaram no computador, que ganharam um jogo novo. Aqui na escola eles não utilizam meios eletrônicos e estando no primeiro ano, não trazem celulares (professora do $1^{\circ}$ ).

Não interfere nada na minha prática. Os alunos não trazem nada eletrônico para a escola. Eu percebo que eles são muito ligados, por causa das conversas e dos debates. Eles sempre inserem algum conhecimento dentro desse tema, que eu aproveito para discutir dentro da sala de aula. Eu percebo sim que eles gostam, sabem entendem e sabem manusear melhor do que o professor. Já utilizei a sala de multimídia, para desenvolver um determinado tema, com visualizações de vídeos no YouTube. $\mathrm{E}$ os alunos que me ensinaram como utilizar esse recurso (professora do $5^{\circ}$ ).

Não dá para negar a influência, mas o mais importante é a relação professor aluno, a aprendizagem a partir do questionamento dos alunos e dos professores. Aquilo que eles vivenciam não é encontrado na internet. Por exemplo: a professora de ciências do fundamental leva os alunos ao laboratório para realizar experiências e depois pede relatórios. A professora de geografia está fazendo um terrário; também fez um experimento com rochas para que os alunos fizessem um livro de classificação. Eles analisaram o brilho da rocha, a cor da rocha, a transparência e o peso. Trabalhamos muito a parte prática do conhecimento. A professora de matemática, para trazer os números negativos e positivos, trabalhou com os dados. Talvez um jogo 
eletrônico possa usar isso, mas a vivência em sala de aula isso não interfere. A parte de pesquisa sim é possível usar a internet. O professor até sugere e orienta (professora do $9^{\circ}$ ).

As três professoras da escola freireana direcionaram suas respostas a como estão lidando com a temática em suas aulas. Todas apresentaram o diálogo como a principal ferramenta para conduzir suas práticas; por meio dele aprimoram os debates, conduzem atividades experimentais e projetos que estimulem o interesse dos alunos pela vivência ativa dos conteúdos.

Freire (2014a) defende que o sonho que nos anima é democrático e solidário, não é falando aos outros, de cima para baixo, sobretudo, como se os professores fossem os portadores da verdade a ser transmitida aos demais, que se aprende a escutar, mas é escutando que se aprende a falar com os educandos. Somente quem escuta paciente e criticamente o outro, fala com ele, mesmo que, em certas condições, precise falar a ele. E Freire continua (2014a, p. 111), "o educador que escuta aprende a difícil lição de transformar o seu discurso, às vezes necessário, ao aluno, em uma fala com ele".

A partir das respostas das professoras em relação dialógica com os princípios pedagógicos freireanos, o aspecto epistêmico tornou-se presente. A pedagogia freireana corresponde a uma ideologia humanista em sua constituição, baseada em memória histórica, parafraseia o que foi dito, no que se está dizendo naquele momento dado, em condições dadas, permite formulações atualizadas, polissêmicas, ou seja, uma ruptura, inauguração de um sentido outro, interpretativo (ORLANDI, 2009).

Como a própria professora e pesquisadora Orlandi (2009) afirma que, se o real em nossa língua não fosse sujeito a falhas e o real da história não fosse passível de rupturas, não haveria transformação, nem movimento dos sujeitos e dos sentidos; portanto, para destrinchar as dimensões que norteiam essa reflexão sobre as pistas dos princípios pedagógicos de Freire, assumimos nosso lugar como professoras e viventes no desafio de educar imerso nesta realidade pulsante.

Ao analisar aspectos materiais, institucionais e epistêmicos, aprendemos, com os princípios pedagógicos freirianos e com as professoras que participaram desta pesquisa, que para conseguir trabalhar coletivamente em nome de um ideal, faz-se essencial entregar-se amorosamente às próprias ações e ressignificar as experiências problematizando-as; pois, por meio de uma linguagem, de uma sociedade e de uma ideologia, tudo dependerá das pessoas que vivem e atuam dentro dessas instituições.

\section{Considerações finais}

Acreditamos que os novos meios discentes de se comunicar devem ser problematizados nos tempos e espaços escolares no intuito de ressignificar as aprendizagens do mundo e sobre o mundo (MELO; TOSTA, 2008). Antigamente as crianças e jovens vivenciavam na prática, com toda sua corporeidade, a expansão, a imaginação e a criatividade das brincadeiras de rua, a escola trazia a disciplina, a forma, a importância dos conteúdos clássicos, numa relação hierárquica entre professor e aluno. Hoje a direção se inverteu, a escola precisa estimular a expansão, a imaginação e a criatividade, além da relação interpessoal, entre os próprios alunos e entre os alunos e os professores.

Esta pesquisa nos flexibilizou quanto ao uso das mídias pelos alunos, não de forma ilimitada, até porque todo excesso é prejudicial, a compulsão de estar sempre plugado, ligado, on-line; mas no sentido de reconhecimento do contexto discente, como uma abertura respeitosa ao outro. Nossa nova realidade comunicacional está alterando, não só as relações, mas a organização do pensamento das novas gerações e essa pauta precisa estar inserida na discussão formativa docente. Reconhecemos que a tecnologia se desenvolve para facilitar a vida humana 
e defendemos que ela faça parte das rodas de conversas sobre prática pedagógica, para que possamos atuar de forma responsável, ao promover o impulso individual para a exteriorização do conhecimento.

Testemunhar a abertura aos outros, a disponibilidade curiosa à vida, a seus desafios, são saberes necessários à prática educativa. Viver a abertura respeitosa aos outros e, de quando em vez, de acordo com o momento, tomar a própria prática de abertura ao outro como objetivo da reflexão crítica deveria fazer parte da aventura docente. A razão ética da abertura, seu fundamento político, sua referência pedagógica; a boniteza que há nela como viabilidade do diálogo (FREIRE, 2014a, p. 133).

Paulo Freire nos ensinou a focar no contexto social que os alunos estão imersos para, como docentes, permearmos nossas práticas de debates, conversas e vivências, a partir de todas as possibilidades de encontros. A contribuição maior de seus princípios pedagógicos é seu principal diferencial, a autonomia de atuação, que permite a abertura ao novo, à pergunta e à reflexão. A ausência de material pedagógico pronto e rígido, como obrigatoriedade de livros didáticos e apostilas, dá asas a seus professores, a partir de discussões e trocas sobre seus alunos, suas realidades e consequentemente, suas práticas.

Iniciamos a pesquisa, com uma verdade enraizada, radicalizada na convicção dos malefícios das mídias no processo educacional como meios de comunicação, disposta a confirmar essa certeza pouco epistemológica. Freire (2014a) incentiva-nos à experiência, sem medo nem preconceito. Aprendemos com essa escola, seus profissionais e com os aportes teóricos de Paulo Freire, que a significância do ato pedagógico vai além de recursos didáticos, estratégias de ensino e dos meios midiáticos, pois a diferença está em fazer com que o ato de ensino e aprendizagem emerja das necessidades reais e concretas dos sujeitos historicamente situados com sede de conhecimento, verdade, ciência e arte.

\section{Referências}

CAREGNATO, Rita Catalina Aquino; MUTTI, Regina. Pesquisa Qualitativa: Análise de Discurso versus Análise de Conteúdo. Texto Contexto Enfermagem, Florianópolis, v. 15, n. 4, p. 679-684, out./dez. 2006.

DUVAL, Evelyn Millis. A Criança e o Rádio; v.13 da Enciclopédia - O Mundo da Criança. Tradução Iva Waisberg Bonow. Rio de Janeiro: Editora Delta, 1949.

FREIRE, Paulo. Pedagogia da autonomia: saberes necessários à prática educativa. 48. ed. Rio de janeiro: Paz e Terra, 2014a.

FREIRE, Paulo. Pedagogia do oprimido. 56. ed. Rio de Janeiro: Paz e terra, 2014b.

GADOTTI, Moacir. Boniteza de um sonho: ensinar-e-aprender com sentido. 2. ed. São Paulo: Editora e Livraria Instituto Paulo Freire, 2011.

GINZBURG, Carlo. Mitos, emblemas e sinais: morfologia e História. São Paulo: Companhia das Letras, 1989.

LÜDKE, Menga; ANDRÉ, Marli. Pesquisa em Educação: abordagens qualitativas. São Paulo: EPU, 2011. 
MARTÍN-BARBERO, Jesús. A comunicação na educação. Tradução: Maria Immacolata Vassalo de Lopes e Dafne Melo. São Paulo: Contexto, 2004.

MELO, José Marques de; TOSTA, Sandra Pereira. Mídia \& Educação. Belo Horizonte: Autêntica Editora, 2008.

ORLANDI, Eni Puccinelli. Análise de Discurso: princípios \& procedimentos. 8. ed. Campinas: Pontes, 2009.

SANTAELLA, Lucia. Comunicação ubíqua: repercussões na cultura e na educação. São Paulo: Paulus, 2013.

SIBILIA, Paula. Redes ou paredes: a escola em tempos de dispersão. Tradução de Vera Ribeiro. Rio de Janeiro: Contraponto, 2012.

VALVERDE, José Maria. História do pensamento: das origens à idade média. Tradução Luiz João Gaia. São Paulo: Nova Cultura, 1987. 